Article

\title{
Optimization and Analysis of a U-Shaped Linear Piezoelectric Ultrasonic Motor Using Longitudinal Transducers
}

\author{
Hongpeng Yu, Qiquan Quan *, Xinqi Tian and He Li \\ School of Mechatronics Engineering, Harbin Institute of Technology, Harbin 150001, China; \\ 17S008010@stu.hit.edu.cn (H.Y.); tianxinqi@hit.edu.cn (X.T.); 17B908020@stu.hit.edu.cn (H.L.) \\ * Correspondence: quanqiquan@hit.edu.cn; Tel.: +86-451-8641-7891
}

Received: 19 January 2018; Accepted: 5 March 2018; Published: 7 March 2018

\begin{abstract}
A novel U-shaped piezoelectric ultrasonic motor that mainly focused on miniaturization and high power density was proposed, fabricated, and tested in this work. The longitudinal vibrations of the transducers were excited to form the elliptical movements on the driving feet. Finite element method (FEM) was used for design and analysis. The resonance frequencies of the selected vibration modes were tuned to be very close to each other with modal analysis and the movement trajectories of the driving feet were gained with transient simulation. The vibration modes and the mechanical output abilities were tested to evaluate the proposed motor further by a prototype. The maximum output speed was tested to be $416 \mathrm{~mm} / \mathrm{s}$, the maximum thrust force was $21 \mathrm{~N}$, and the maximum output power was $5.453 \mathrm{~W}$ under frequency of $29.52 \mathrm{kHz}$ and voltage of $100 \mathrm{~V}_{\text {rms }}$. The maximum output power density of the prototype reached $7.59 \mathrm{~W} / \mathrm{kg}$, which was even greater than a previous similar motor under the exciting voltage of $200 \mathrm{~V}_{\mathrm{rms}}$. The proposed motor showed great potential for linear driving of large thrust force and high power density.
\end{abstract}

Keywords: piezoelectric ultrasonic motor; finite element method; longitudinal vibration; high power density

\section{Introduction}

Piezoelectric ultrasonic motors (PUMs) have developed rapidly in the recent 40 years with the increasing demands of the actuators in engineering applications [1,2]. They drive the runners or rotors with the frictional forces that are generated by the specific movements of the driving feet, which are excited via the vibrations of the piezoelectric elements. They show the merits of small size, simple structure, high power weight ratio, high accuracy and resolution, quick response, self-locking when power off, and a lack of electromagnetic radiation [3-6]. Hence, they have been successfully used in the field of high-tech and civilian use, such as robot driving, high precision machine, micro electro mechanical system (MEMS), and digital camera autofocus system $[7,8]$.

The elliptical-trajectory movements of the driving tips are generally generated for the purpose to obtain the stable frictional forces to drive the runners or rotors [9]. PUMs can be divided into three types: traveling wave ultrasonic motors [10-17], standing wave ultrasonic motors [18-20], and composite vibrations ultrasonic motors [21,22], according to the ways to generate the elliptical-trajectory movements. Generally, the PUMs using composite vibrations have simple structures, large thrust force, and high output speed, so they have become more popular in recent years. Furthermore, this type of PUMs usually uses the modes of longitudinal and bending hybrid vibrations $[23,24]$, longitudinal and torsional hybrid vibrations [25-27], two orthogonal longitudinal hybrid vibrations [28-32], and two orthogonal bending hybrid vibrations [33-36] to form the elliptical-trajectory movements. 
Liu et al. proposed a very novel linear ultrasonic motor using the hybrid of two orthogonal longitudinal vibrations [37]. Their motor had three transducers, and two vibration modes which were orthogonal in space and had a phase shift of $90^{\circ}$ in time were selected to generate the elliptical movements on the driving feet. The prototype had a total length of $170 \mathrm{~mm}$, height of $107.5 \mathrm{~mm}$, and weight of $1.42 \mathrm{~kg}$. The typical mechanical output abilities of it were the no-load output speed of $854 \mathrm{~mm} / \mathrm{s}$ and the maximum thrust force of $40 \mathrm{~N}$ with the voltage of $200 \mathrm{~V}_{\text {rms. However, this }}$ ultrasonic motor was large in size and complicated in fabrication.

This work proposed a novel U-shaped PUM focusing on high power density, miniaturization, and simple assembly technique. The novel PUM also used a bolt-clamped structure to get the high output speed and large thrust force. However, a lot of changes had been designed for the purpose of optimization, which included smaller dimensions, lighter weight, simpler assembly processing, and higher output power density. In addition, the maximum output speed and the maximum output thrust force had very important influence on the characteristics of the PUM, so they were considered adequately, too. The structure and operating principle were discussed to describe the novel PUM. The simulated analyses, including modal analysis and transient simulation, were developed to tune the resonance frequencies and obtain the elliptical movements of the particles on the driving surfaces. The vibration mode shapes and mechanical output abilities were tested to evaluate the PUM further after fabricating a prototype. The comparison of the performances between the novel PUM and the previous similar one was given and discussed in the end to draw the conclusion of this work.

\section{Structural Optimum of the PUM}

The three-dimensional structure and overall dimensions of the proposed motor is shown in Figure 1. The PUM consists of one horizontal transducer and two vertical ones located in U-shape, which are designed to work with their longitudinal resonant vibration modes. The bolt-clamped structure is adopted in order to obtain the high output speed and large thrust force. Strong preload can be applied on the ceramics and fatigue of the adhesive layer can be avoided by using this structure. The longitudinal vibration modes of the transducers are excited by the $\mathrm{d}_{33}$ working mode of PZT ceramics, which is most direct and efficient because of its high electromechanical coupling efficiency. All the PZT ceramics are polarized along their thickness directions, and their polarizations are also shown in Figure 1. The horns of the PUM are designed into exponential shapes to magnify the vibration amplitudes and velocities, so that more mechanical vibration energies can enter the frictional coupling process. Besides all above, there are some beryllium bronze sheets serving as electrodes for applying the exciting voltage on the ceramics.

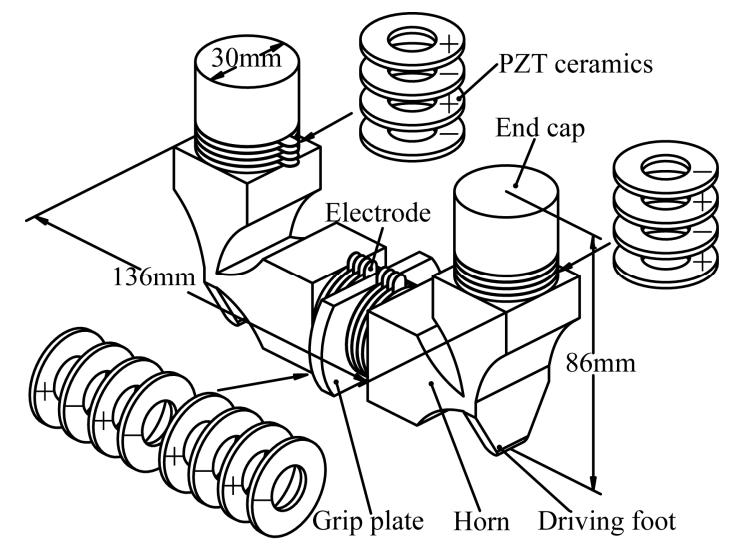

Figure 1. The three-dimensional structure of the modified piezoelectric ultrasonic motors (PUM).

The structures mentioned above are similar to the previous motor proposed by Liu et al. [37]. However, there are many obvious differences. First of all, the dimensions of the novel PUM are 
decreased in comparison with the previous one. As a result, the volume and weight of the motor can be reduced, which is to be the benefit of engineering applications. The decrease of dimensions will lead to the increase of resonance frequencies in the light of vibration theory, so the working frequency of the novel motor will get higher. It may be conducive to the improvement of the output speed and the output power density. Secondly, the assembly technique of the novel motor has been simplified a lot. It is known that the two horns were connected with a stud bolt in the previous structure that was designed by Liu et al. This structure causes the result that the pretightening moment of the bolt is difficult to control and the two driving feet cannot be assured to be parallel to each other, which will result in the poor performance of the PZT ceramics and the abrasion of the driving surfaces. So, the assembly technique of secondary processing is adopted in the novel structure to solve the problem. The motor should be fabricated as the structure showed in Figure 2a preliminarily, and it can then be machined into the structure showed in Figure $2 b$ with the method of Wire Electric Discharge Machining (WEDM). In this way, the pretightening moment of the bolt can be controlled easily, and the depth of parallelism between the two driving feet can be up to a very high level, which is beneficial to simplify the assemblage and to improve the performances of the PUM. In addition, the end caps and the PZT ceramics are all designed into cylinder-shape, which makes the machining progress easier and the assembly precision higher. This change can reduce the cost drastically. Furthermore, the bumped plates on the flange are designed for the gripper to fix the motor and to apply preload force between the motor and runner. They could provide reliable and high-stiffness clamping, which is good for generating better vibration modes and performances. Last but not least, the driving feet are machined into trapezoid-shape to ensure the particles on the contact surfaces have close vibration amplitude. The tips of the driving feet are designed into cylinder-shape to ensure the contact area between the driving feet and runner remains unchanged during the vibration progress. All in all, these optimizations of structure are all designed to achieve the objective elaborated above.

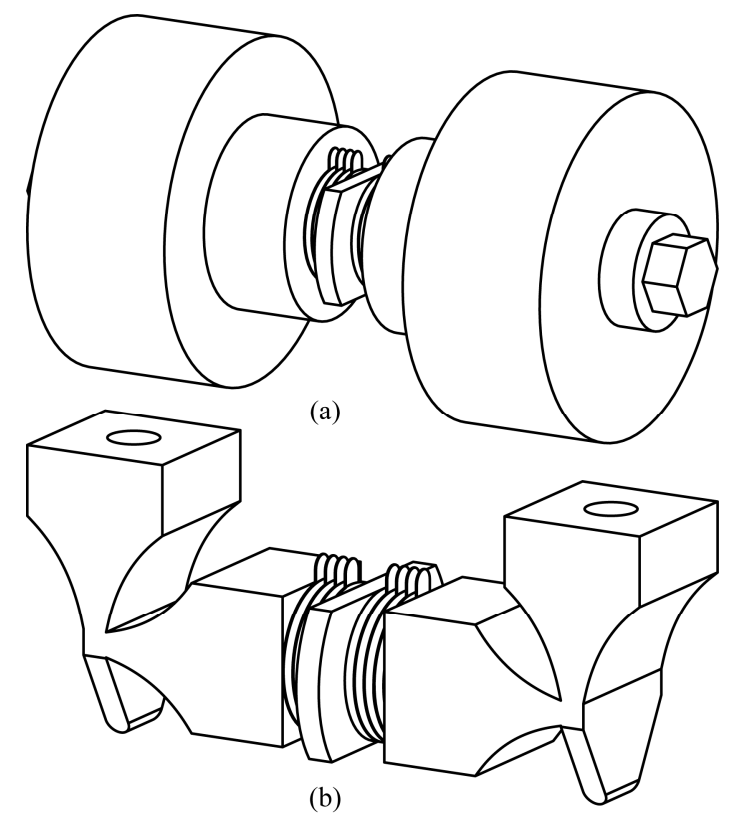

Figure 2. The assembly technique of the modified PUM: (a) The structure before secondary processing; and, (b) The structure after secondary processing.

\section{Operating Principle of the Driving Effect}

The vibration modes must be selected reasonably in order to generate the elliptical movements with driving effect on the driving feet. According to the vibration theory, the higher the vibration order is, the smaller the vibration amplitude will be. So, the vibration order should be as low as 
possible to gain the high output speed and efficiency. At the same time, the vibration modes have to satisfy the essential requirements of PUM. Hence, the two vibration modes that are shown in Figure 3 are selected to superimpose the elliptical movements. Mode A in Figure 3 is the vibration mode that is excited by the longitudinal vibration of the horizontal transducer, which results in the horizontal displacements of the driving feet; mode B in Figure 3 is the vibration mode that is excited by the longitudinal vibrations of the vertical transducers, which results in the vertical displacements of the driving feet. The vibrations are both caused by the stretching-contracting movements of the PZT ceramics when alternating voltage is applied on them. As seen in Figure $3 a, b$, the vibration directions of the two driving feet are both converse, which are ensured by the structure of the PUM and the polarization of the PZT ceramics, respectively. Besides, the actual vibrations of the transducers are longitudinal-bending vibrations, because the coupling vibrations occur in the PUM. When the resonance frequencies of the two modes are nearly equivalent, the superposition of them will happen with the excitation of specific voltage.

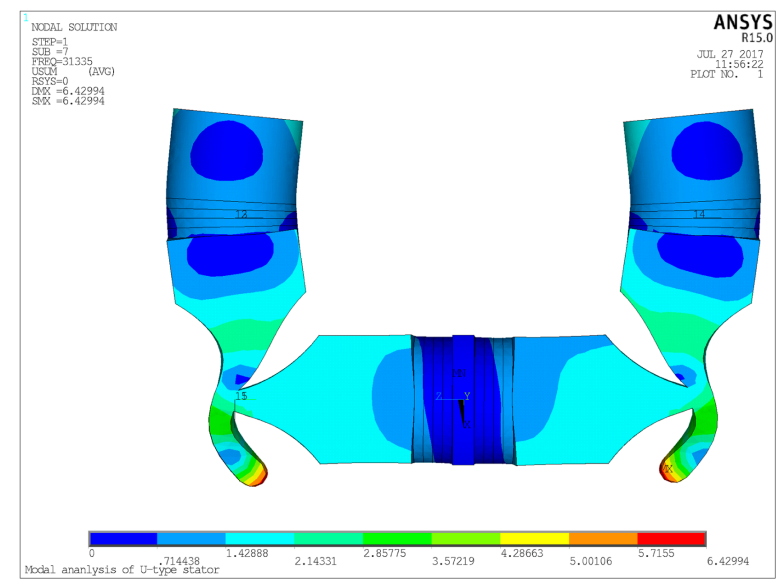

(a)



(b)

Figure 3. Vibration modes of the PUM: (a) Mode A; and, (b) Mode B.

The resultant motion will be an ellipse if the harmonic vibrations of the particles on the driving feet are perpendicular in space and have a phase shift of $\pi / 2$ in time basing on the knowledge of Lissajous figures. So that the movements that are required on the contact surfaces between the motor and runner with driving effect can be obtained. Furthermore, the motions of the two feet have a phase shift of $\pi$ in time. Therefore, the two driving feet can contact with the runner and push it alternatively. The transducers are operated as the steps shown in Table 1 in one vibration period according to the selected vibration modes, and the working principle can be expressed as Figure 4 intuitively. The deformation of the motor changes from status 1 to status 2 when $t$ is before and after 
$n T$ according to Table 1 and Figure 4. The right driving foot keeps contacting with the runner and pushing it with frictional force in one direction in this process. The deformation of the motor becomes status 3 when $t$ reaches $(n+1 / 4) T$. The two driving feet both contact with the runner and the motor has no driving effect at this moment exactly. Then, the deformation of the motor changes from status 4 to status 5 when $t$ is before and after $(n+1 / 2) T$. The left driving foot keeps contacting with the runner and pushing it with frictional force in the direction that is identical with the right one in this process. The deformation of the motor becomes status 6 when $t$ reaches $(n+3 / 4) T$. The two driving feet both contact with the runner and the motor has no driving effect at this moment exactly. As a result, the elliptical-trajectories of the particles on the driving feet are generated in the circulation from status 1 to status 6 , and the runner is pushed to move in a specific direction. Furthermore, the elliptical motions will be reversed, and the motion in the opposite direction of the runner can be realized on condition that the phase shift of the two vibration modes changes from $\pi / 2$ to $-\pi / 2$.

Table 1. The vibration statuses of the transducers in one period.

\begin{tabular}{|c|c|c|c|c|c|}
\hline Time & $\begin{array}{l}\text { Left Vertical } \\
\text { Transducer }\end{array}$ & $\begin{array}{l}\text { Right Vertical } \\
\text { Transducer }\end{array}$ & $\begin{array}{l}\text { Horizontal } \\
\text { Transducer }\end{array}$ & $\begin{array}{c}\text { Vertices on } \\
\text { Left Feet }\end{array}$ & $\begin{array}{l}\text { Vertices on } \\
\text { Right Feet }\end{array}$ \\
\hline$t=n T^{1}$ & Shortened & Extended & Normal & Top & Bottom \\
\hline$t=(n+1 / 4) T$ & Normal & Normal & Shortened & Left & Right \\
\hline$t=(n+1 / 2) T$ & Extended & Shortened & Normal & Bottom & Top \\
\hline$t=(n+3 / 4) T$ & Normal & Normal & Extended & Right & Left \\
\hline
\end{tabular}

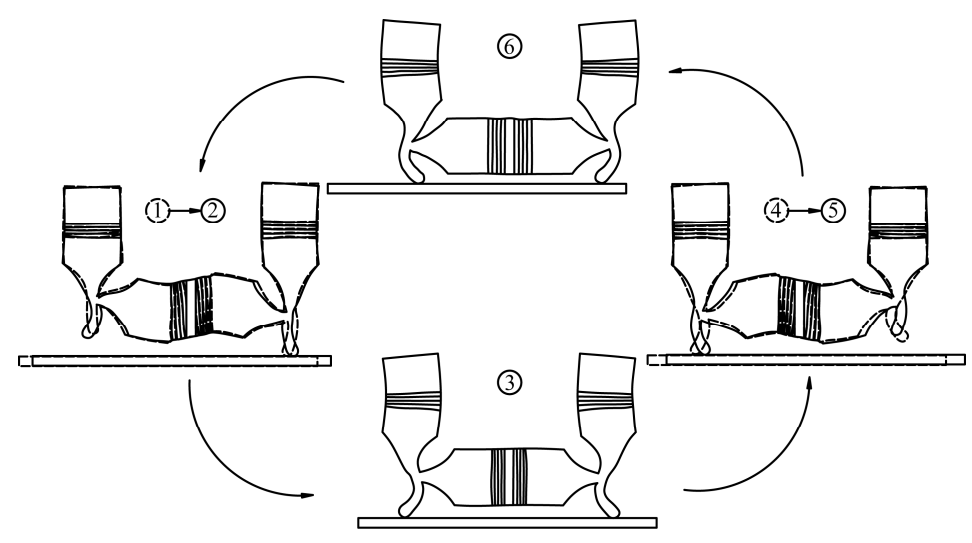

Figure 4. The working principle of the proposed PUM.

\section{Dimensional Design and Simulation Analysis of the PUM}

It is clear that the resonance frequencies of the two selected vibration modes must be nearly equivalent to ensure the proper operation with the aforementioned operating principle. So, the structural parameters should be designed elaborately to accomplish this objective. FEM was used to tune the resonance frequencies by modal analysis with ANSYS software. The finite element modal with the designed materials was conducted as the structure showed in Figure 1. The exciting voltage of the PZT ceramics was set as zero, and Block Lanczos method was used to extract the analysis results. The selected vibration modes were excited by applying the fixing boundary conditions on the surfaces of the flange. The optimal structural parameters were obtained after several times of iteration, and the resonance frequencies of the longitudinal vibrations of the horizontal and vertical transducers were calculated to be $31.335 \mathrm{kHz}$ and $31.352 \mathrm{kHz}$, respectively. There was a very small discrepancy of $0.017 \mathrm{kHz}$ between the two frequencies, so that the conditions of superimposing Lissajous Figures could be satisfied and the resonance frequency of the whole motor could be seen as 
$31.3 \mathrm{kHz}$, theoretically. However, the real resonance frequency and the optimal working frequency must be tested in the experiments.

The transient simulation was developed based on the structural parameters that were designed by modal analysis to investigate the motion behaviors of the particles on the driving surfaces. Sine and cosine exciting voltages with effective value of $100 \mathrm{~V}$ and frequency of $31.344 \mathrm{kHz}$ were applied on the two groups of PZT ceramics in the simulation according to the operating principle illuminated above. The motion trajectories in the XOZ plane of the selected points on the two driving surfaces can be obtained when the status of the vibration got stable (after about $3 \mathrm{~ms}$ of simulation time). The point selections are shown in Figure $5 \mathrm{a}$ and the motion trajectories are shown in Figure $5 \mathrm{~b}$. The phenomenon can be recognized clearly as follows, according to Figure 5. Firstly, the motion trajectories of the points on the driving surfaces are ellipses exactly, which agrees with the theoretical analysis. As a result, it is preliminarily verified that the dimensional design is correct and the driving effect of the PUM is feasible. Secondly, the motion trajectories of different points on the driving surfaces are nearly concordant, which is a great improvement. This improvement can decrease the relative sliding between the PUM and the runner, so that the efficiency of the friction coupling progress and the output speed of the PUM will be increased. The improvement of the characteristic will be measured in the experiments. In addition, there is a phenomenon that is different from the theoretical analysis that the axes of the two ellipse-trajectories are not coincident with each other. It is because that the coupling bending vibrations between different transducers and the phase lags that are caused by structural damping exist in the PUM, and they are different in the three transducers. Hence, the ideal conditions for the superimposition of Lissajous Figures cannot be satisfied, which results in that phenomenon. In spite of this, the motion still has driving effect and the influence on the characteristic can be evaluated in the experiments.
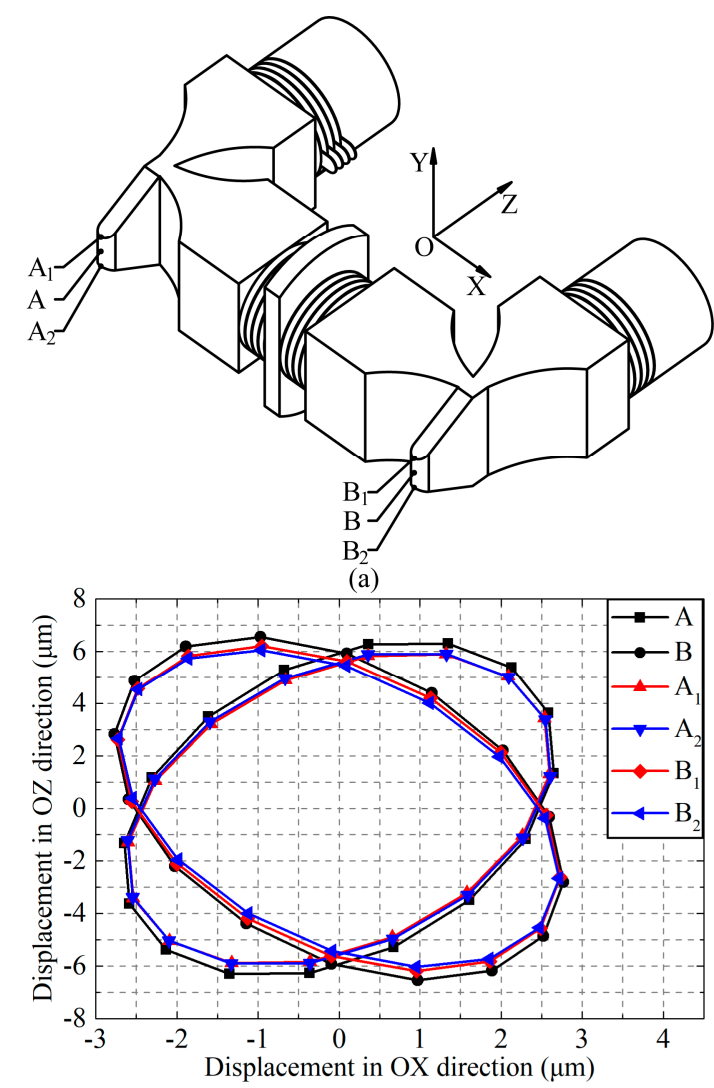

(b)

Figure 5. The motion trajectories of the driving surfaces: (a) Point selections; and, (b) Motion trajectories of the selected points. 


\section{Experimental Evaluation of the PUM}

A prototype was fabricated to conduct the experiment for the purpose of evaluating the characteristics and validating the improvement of the optimized PUM. The vibration characteristic was a crucial factor to impact the driving performance of the PUM, so an SLDV (Scanning Laser Doppler Vibrometer) was used to measure the vibration characteristic of the prototype. The prototype was fixed by the grip plate when the exciting voltage was applied on it, and the test region should be perpendicular to the laser. The coupling bending vibrations excited by the longitudinal ones were measured considering the simplification and accuracy of the measurement. The vibration mode shapes and vibration velocity response spectrums are shown in Figure 6.

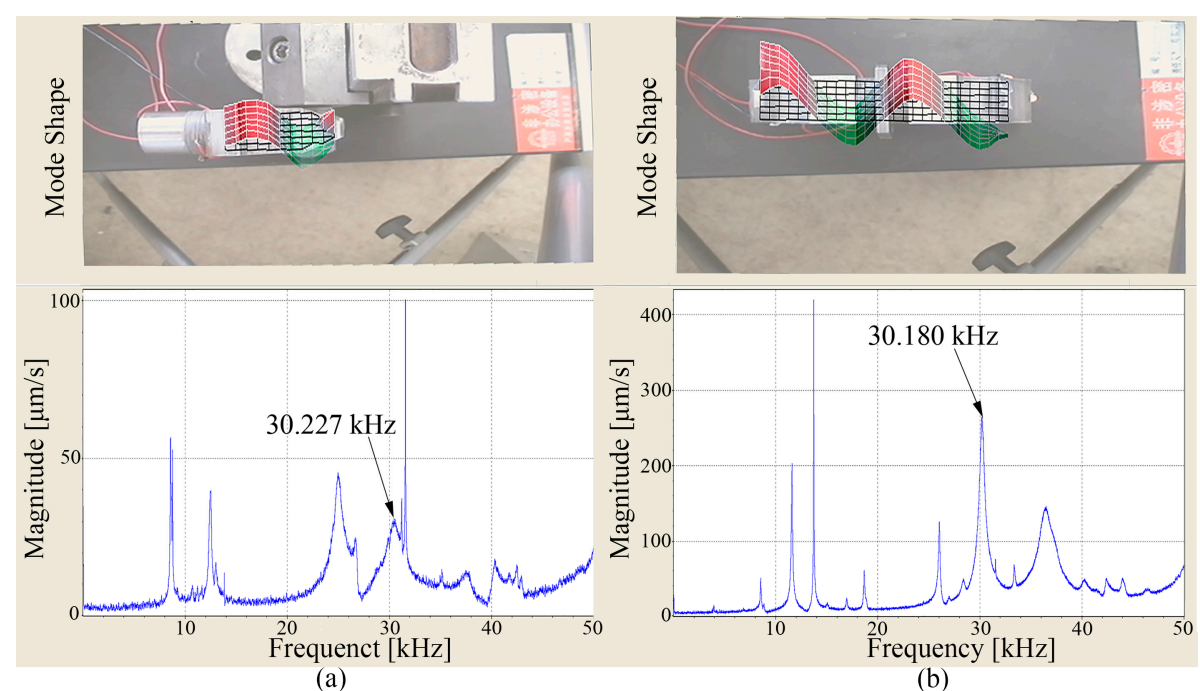

Figure 6. The results of vibration scanning: (a) The coupling bending vibrations of the vertical transducers; (b) The coupling bending vibration of the horizontal transducer.

Figure 6a shows the vibration characteristic of mode A. In view of the accuracy of the measurement, the plane part of the surface was selected as the test region. Figure $6 \mathrm{~b}$ shows the vibration characteristic of mode B. It can be known that the vibrations of the transducers are longitudinal-bending vibrations exactly according to the mode shapes, and the bending component is caused by the longitudinal one. The vibration mode shapes are in good agreement with the theoretical analysis, which verify the validity of the design and analysis. The response frequencies of mode A and mode $\mathrm{B}$ are tested to be $30.227 \mathrm{kHz}$ and $30.180 \mathrm{kHz}$ on the basis of the response spectrums, respectively. There is a difference of $0.047 \mathrm{kHz}$ between the two frequencies, which indicates the good degeneration of the two selected vibration modes. The two response frequencies can be thought as identical with the ones from modal analysis by taking the error from simulation and experiment in consideration, and the working frequency of the PUM can be thought as about $30.2 \mathrm{kHz}$.

The mechanical output abilities of the prototype were tested with the instruction of the vibration test. An experimental platform was designed and fabricated for the prototype. The platform with the prototype is shown in Figure 7. The prototype was fixed on the platform by a gripper. A guide was adopted to ensure the linear motion of the runner. The preload between the driving feet and the runner was applied by a plate spring. 


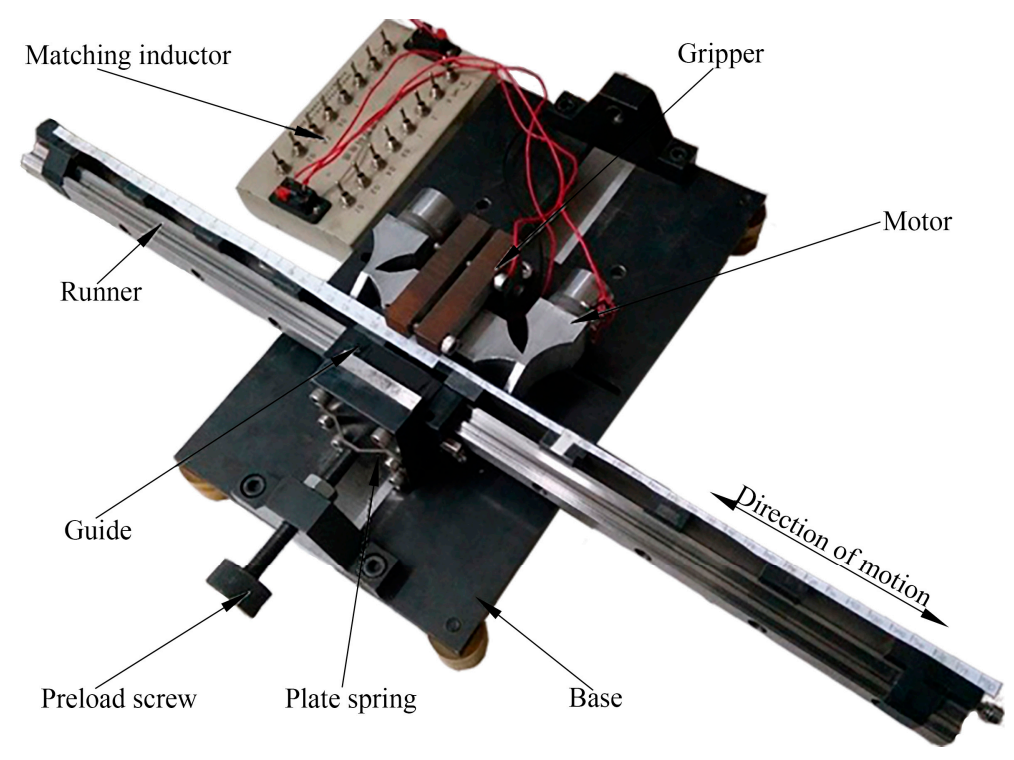

Figure 7. The prototype and experimental platform of the proposed PUM.

Firstly, the experimental installation was fabricated and the preload between the driving feet and runner was adjusted to be about $100 \mathrm{~N}$ to obtain the relatively best mechanical output ability, so as to achieve the maximum output power density. Then, the measurement of the frequency versus no-load speed was carried out with the following conditions: the phase shift of the exciting voltage was $90^{\circ}$ and the amplitude of the exciting voltage was $100 \mathrm{~V}_{\mathrm{rms}}$. The frequency-speed characteristic was obtained by changing the frequency of the exciting voltage from $28.74 \mathrm{kHz}$ to $30.47 \mathrm{kHz}$, as shown in Figure 8a. The output speed is fastest when the frequency is about $29.4-29.7 \mathrm{kHz}$, according to the curve in Figure 8a, so the optimal working frequency of the prototype is set as $29.52 \mathrm{kHz}$, which has a very small difference from the modal analysis or vibration test. It is because of the errors that are caused by machining and simulation, but the influence of it is very small.

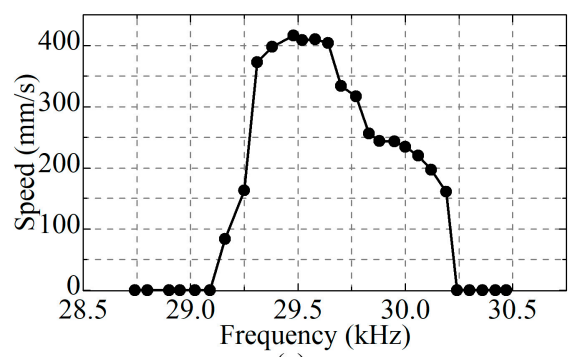

(a)

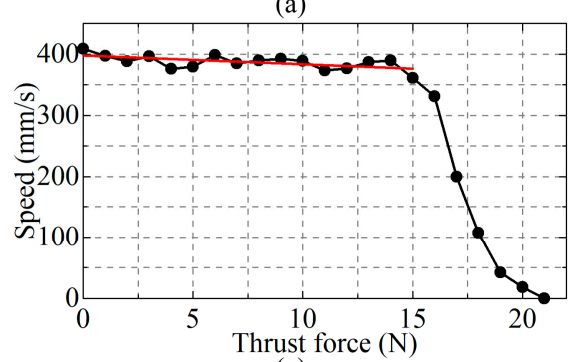

(c)

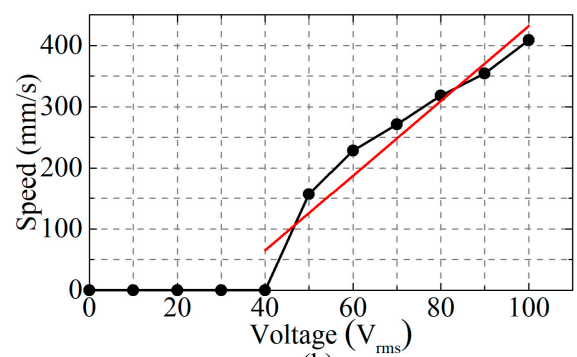

(b)

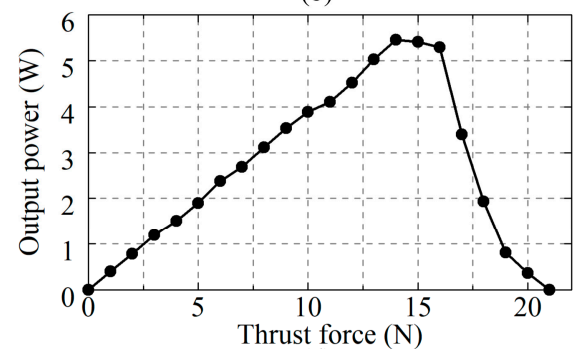

(d)

Figure 8. The mechanical output abilities of the prototype: (a) Frequency-speed characteristic; (b) Voltage-speed characteristic; (c) Thrust force-speed characteristic; and, (d) Thrust force-output power characteristic. 
Next, the voltage-speed characteristic was measured in conditions of keeping the frequency of the exciting voltage being $29.52 \mathrm{kHz}$ and the phase shift of the exciting voltage being $90^{\circ}$, as shown in Figure $8 \mathrm{~b}$. It can be found that the threshold voltage is about $40 \mathrm{~V}_{\mathrm{rms}}$ and the no-load speed increases when the amplitude of the exciting voltage gets higher than the threshold voltage. Besides, the no-load speed and the amplitude of the exciting voltage fit a good linear relation, which makes the PUM easy to control in engineering applications.

Additionally, the thrust force was changed to measure the speed of the PUM with the frequency of the exciting voltage of $29.52 \mathrm{kHz}$, the amplitude of $100 \mathrm{~V}_{\mathrm{rms}}$ and the phase shift of $90^{\circ}$. The thrust force-speed characteristic is shown in Figure 8c. It indicates that the physical characteristic of the PUM is very hard when the thrust force is smaller than $15 \mathrm{~N}$, which is a good improvement of this PUM in engineering applications. The speed decreases when the thrust force is too big, and the fastest speed is no-load speed as $416 \mathrm{~mm} / \mathrm{s}$, the maximum thrust force is $21 \mathrm{~N}$. Actually, the ideal characteristics of the PUM will be better than above when considering the friction between the guide and the runner.

The thrust force-output power characteristic of the prototype was obtained in accordance with the thrust force-speed characteristic, as shown in Figure 8d. The output power of the prototype increases first and then decreases with the increase of the thrust force. The maximum output power of the prototype can reach $5.453 \mathrm{~W}$ when the thrust force is $14 \mathrm{~N}$. The weight of the prototype is $0.718 \mathrm{~kg}$, so the maximum output power density of the prototype is $7.59 \mathrm{~W} / \mathrm{kg}$.

The mechanical output abilities of the prototype can be seen clearly according to the curves shown in Figure 8. Generally, a higher exciting voltage can be applied on the PZT ceramics and the preload between the driving feet and runner can be increased because the bolt-clamped structure can apply strong preload on the PZT ceramics and avoid the fatigue of the adhesive layer. As a result, faster speed and larger thrust force can be achieved, theoretically. Besides, applying the friction materials can also improve the performances of the PUM. These characteristics show the merits of this new configuration for linear driving and the good potential of the proposed PUM in engineering applications.

The comparison between the previous PUM [37] and the optimized one in this work is shown in Table 2. It can be known that the dimensions and weight of the PUM have been decreased and the quantity of the PZT ceramics has been reduced a lot, all of which accomplish the objective of miniaturization. The exciting voltage applied on the optimized PUM is $100 \mathrm{~V}_{\mathrm{rms}}$, which is only half of the previous similar one; this condition makes the electric field densities of the PZT ceramics in these two motors be the same, under which these two motors can be evaluated with a good standard. This improvement reduces the demands of the power supply dramatically, which is a benefit to the integration of the whole driving system. The maximum speed of the optimized PUM is $49 \%$ and the maximum thrust force is $53 \%$ of the previous one with the voltage described above. This optimized PUM can also apply to the situations which need high speed and large thrust force because the output speed and the thrust force will increase with higher voltage and larger preload. At the same time, the output power will raise concomitantly with the increase of the exciting voltage. Hence, the objective of high power density is accomplished. The reasons causing the improvement can be summarized as follows basing on the modification of the PUM. First of all, the decrease of dimensions makes the resonance frequency of the optimized PUM get higher, which increases the vibration energy of the PUM with the same amplitude of voltage. Secondly, the motion trajectories of the particles on the driving surfaces have better conformance, so almost all of the particles on the interface can drive the runner synchronously, which increases the efficiency of the energy transforming in the friction coupling progress. In addition, the stiffness of the clamping condition in the new structure has been increased, so less vibration energy loses via the grip and larger preload can be applied on the driving surfaces. These factors above improve the performance of the PUM synthetically. 
Table 2. The comparison between the previous similar PUM and the optimized one.

\begin{tabular}{ccc}
\hline Item & Previous PUM [37] & Optimized PUM \\
\hline Working frequency $(\mathrm{kHz})$ & 23.59 & 29.52 \\
Total length $(\mathrm{mm})$ & 170 & 136 \\
Total height $(\mathrm{mm})$ & 107.5 & 86 \\
Weight $(\mathrm{kg})$ & 1.42 & 0.718 \\
Quantity of PZT ceramics $\left(\mathrm{mm}^{3}\right)$ & 51411 & 17693 \\
Amplitude of exciting voltage $\left(\mathrm{V}_{\mathrm{rms}}\right)$ & 200 & 100 \\
Maximum speed $(\mathrm{mm} / \mathrm{s})$ & 854 & 416 \\
Maximum thrust force $(\mathrm{N})$ & 40 & 21 \\
Maximum power $(\mathrm{W})$ & 10.39 & 5.453 \\
Maximum power density $(\mathrm{W} / \mathrm{kg})$ & 7.32 & 7.59 \\
\hline
\end{tabular}

\section{Conclusions}

An improved and miniaturized U-shaped linear piezoelectric ultrasonic motor was proposed, fabricated, and tested, and the operating principle of the proposed PUM was analyzed. The new structure of the PUM was more suitable for machining and assembly, and the clamping condition got better than a previous motor. The dimensions were decreased and the weight was only about $50 \%$ of the previous one. The two selected vibration modes were analyzed and the resonance frequencies of them were tuned to be very close to each other by adjusting the structural parameters with modal analysis. The elliptical motion trajectories of the driving feet were obtained by transient simulation to verify the feasibility of the driving effect. The results of vibration test were in good agreement with the modal analysis, and the resonance frequencies of the two vibration modes were tested to be $30.227 \mathrm{kHz}$ and $30.180 \mathrm{kHz}$, with a small discrepancy of $0.047 \mathrm{kHz}$. The typical output abilities of the prototype showed that the optimal working frequency was about $29.52 \mathrm{kHz}$ with voltage of $100 \mathrm{~V}_{\mathrm{rms}}$. The maximum output speed and maximum thrust force were tested to be about $416 \mathrm{~mm} / \mathrm{s}$ and $21 \mathrm{~N}$, respectively. The maximum output power was about $5.453 \mathrm{~W}$ and the power density was about $7.59 \mathrm{~W} / \mathrm{kg}$, which meant that the power density of the optimized PUM could reach the same level with only half amplitude of the exciting voltage being applied on the previous similar one. All of the results indicate that the desired optimization has been accomplished. Besides, a novel way to improve the power density of the PUM can be summarized from the design procedure in this work.

Acknowledgments: This work was supported in part by the National Natural Science Foundation of China (Grant No. 61403106) and the Program of Introducing Talents of Discipline to Universities (Grant No. B07018).

Author Contributions: This work presented in this paper was a collaboration of all authors. Qiquan Quan conceived this study. Hongpeng Yu and Qiquan Quan developed the FEM calculation, designed the experiments. Hongpeng Yu, Qiquan Quan and Xinqi Tian performed the experiments, analyzed the data and wrote the paper. $\mathrm{He} \mathrm{Li}$ analyzed the data and revised the paper.

Conflicts of Interest: The authors declare no conflict of interest.

\section{References}

1. Peled, G.; Yasinov, R.; Karasikov, N. Performance and applications of L1B2 ultrasonic motors. Actuators 2016, 5, 15. [CrossRef]

2. Tsai, M.S.; Lee, C.H.; Hwang, S.H. Dynamic modeling and analysis of a bimodal ultrasonic motor. IEEE Trans. Ultrason. Ferroelectr. Freq. Control 2003, 50, 245-256. [CrossRef] [PubMed]

3. Zhao, C.S. Ultrasonic Motors: Technologies and Applications, 1st ed.; Science Press: Beijing, China, 2010; pp. 1-10.

4. He, S.Y.; Chiarot, P.R.; Park, S. A single vibration mode tubular piezoelectric ultrasonic motor. IEEE Trans. Ultrason. Ferroelectr. Freq. Control 2011, 58, 1049-1061. [CrossRef] [PubMed]

5. Watson, B.; Friend, J.; Yeo, L. Piezoelectric ultrasonic micro/milli-scale actuators. Sens. Actuator A Phys. 2009, 152, 219-233. [CrossRef]

6. Liu, Y.X.; Chen, W.S.; Liu, J.K.; Yang, X.H. A high-power linear ultrasonic motor using bending vibration transducer. IEEE Trans. Ind. Electron. 2013, 60, 5160-5166. [CrossRef] 
7. Li, H.Y.; Wang, L.; Cheng, T.H.; He, M.; Zhao, H.W.; Gao, H.B. A high-thrust screw-type piezoelectric ultrasonic motor with three-wavelength exciting mode. Appl. Sci. Basel 2016, 6. [CrossRef]

8. Gu, G.Y.; Zhu, L.M.; Su, C.Y.; Ding, H.; Fatikow, S. Modeling and control of piezo-actuated nanopositioning stages: A survey. IEEE Trans. Autom. Sci. Eng. 2016, 13, 313-332. [CrossRef]

9. Hemsel, T.; Mracek, M.; Twiefel, J.; Vasiljev, P. Piezoelectric linear motor concepts based on coupling of longitudinal vibrations. Ultrasonics 2006, 44, E591-E596. [CrossRef] [PubMed]

10. Dong, Z.P.; Yang, M.; Chen, Z.Q.; Xu, L.; Meng, F.; Ou, W.C. Design and performance analysis of a rotary traveling wave ultrasonic motor with double vibrators. Ultrasonics 2016, 71, 134-141. [CrossRef] [PubMed]

11. Liu, Y.X.; Liu, J.K.; Chen, W.S. A cylindrical traveling wave ultrasonic motor using a circumferential composite transducer. IEEE Trans. Ultrason. Ferroelectr. Freq. Control 2011, 58, 2397-2404. [CrossRef] [PubMed]

12. Chen, W.S.; Liu, Y.X.; Yang, X.H.; Liu, J.K. Ring-type traveling wave ultrasonic motor using a radial bending mode. IEEE Trans. Ultrason. Ferroelectr. Freq. Control 2014, 61, 197-202. [CrossRef] [PubMed]

13. Jin, J.M.; Zhao, C.S. A novel traveling wave ultrasonic motor using a bar shaped transducer. J. Wuhan Univ. Technol. Mater. Sci. Ed. 2008, 23, 961-963. [CrossRef]

14. Ro, J.S.; Yi, K.P.; Chung, T.K.; Jung, H.K. Characteristic analysis and shape optimal design of a ring-type traveling wave ultrasonic motor. Eur. Phys. J. Appl. Phys. 2013, 63, 10. [CrossRef]

15. Shen, S.N.; Lee, H.P.; Lim, S.P.; Ong, C.J. Contact mechanics of traveling wave ultrasonic motors. IEEE Trans. Magn. 2013, 49, 2634-2637. [CrossRef]

16. Marquez, I.A.R.; Bolborici, V. A dynamic model of the piezoelectric traveling wave rotary ultrasonic motor stator with the finite volume method. Ultrasonics 2017, 77, 69-78. [CrossRef] [PubMed]

17. Dong, Z.P.; Yang, M. Optimal design of a double-vibrator ultrasonic motor using combination method of finite element method, sensitivity analysis and adaptive genetic algorithm. Sens. Actuator A Phys. 2017, 266, 1-8. [CrossRef]

18. Zhang, Y.H.; Qu, J.J.; Li, J.B. Friction and wear behavior of linear standing-wave ultrasonic motors with v-shape transducers. Tribol. Int. 2016, 95, 95-108. [CrossRef]

19. Zhang, Q.; Chen, W.S.; Liu, Y.X.; Liu, J.K.; Jiang, Q. A frog-shaped linear piezoelectric actuator using first-order longitudinal vibration mode. IEEE Trans. Ind. Electron. 2017, 64, 2188-2195. [CrossRef]

20. Li, X.; Yao, Z.Y.; He, Y.G.; Dai, S.C. Modeling and experimental investigation of thermal-mechanical-electric coupling dynamics in a standing wave ultrasonic motor. Smart Mater. Struct. 2017, 26, 18. [CrossRef]

21. Uchino, K. Piezoelectric Actuators and Ultrasonic Motors, 1st ed.; Kluwer Academic Publishers: Boston, MA, USA, 1996; ISBN 978-0-7923-9811-0.

22. Yun, C.H.; Ishii, T.; Nakamura, K.; Ueha, S.; Akashi, K. A high power ultrasonic linear motor using a longitudinal and bending hybrid bolt-clamped langevin type transducer. Jpn. J. Appl. Phys. Part 1 Regul. Pap. Short Notes Rev. Pap. 2001, 40, 3773-3776. [CrossRef]

23. Yun, C.H.; Niwano, S.; Friend, J.R.; Nakamura, K.; Ueha, S. Support mechanism for the ball rotor in the three-degree-of-freedom ultrasonic motor. Jpn. J. Appl. Phys. Part 1 Regul. Pap. Short Notes Rev. Pap. 2003, 42, 3000-3001. [CrossRef]

24. Park, T.; Kim, B.; Kim, M.H.; Uchino, K. Characteristics of the first longitudinal-fourth bending mode linear ultrasonic motors. Jpn. J. Appl. Phys. Part 1 Regul. Pap. Short Notes Rev. Pap. 2002, 41, 7139-7143. [CrossRef]

25. Yi, Y.P.; Seemann, W.; Gausmann, R.; Zhong, J. A method for matching the eigenfrequencies of longitudinal and torsional vibrations in a hybrid piezoelectric motor. J. Sound Vibr. 2006, 295, 856-869. [CrossRef]

26. Al-Budairi, H.; Lucas, M.; Harkness, P. A design approach for longitudinal-torsional ultrasonic transducers. Sens. Actuator A-Phys. 2013, 198, 99-106. [CrossRef]

27. Park, T.G.; Jeong, D.S.; Kim, M.H.; Song, T.K. A study on the rotary-type ultrasonic motor using a longitudinal-torsional vibration converter. Mater. Chem. Phys. 2006, 98, 1-4. [CrossRef]

28. Liu, Y.X.; Chen, W.S.; Liu, J.K.; Shi, S.J. A rectangle-type linear ultrasonic motor using longitudinal vibration transducers with four driving feet. IEEE Trans. Ultrason. Ferroelectr. Freq. Control 2013, 60, 777-785. [CrossRef] [PubMed]

29. Kurosawa, M.K.; Kodaira, O.; Tsuchitoi, Y.; Higuchi, T. Transducer for high speed and large thrust ultrasonic linear motor using two sandwich-type vibrators. IEEE Trans. Ultrason. Ferroelectr. Freq. Control 1998, 45, 1188-1195. [CrossRef] [PubMed]

30. Liu, Y.X.; Yan, J.P.; Xu, D.M.; Chen, W.S.; Yang, X.H.; Tian, X.Q. An I-shape linear piezoelectric actuator using resonant type longitudinal vibration transducers. Mechatronics 2016, 40, 87-95. [CrossRef] 
31. Liu, Y.X.; Chen, W.S.; Feng, P.L.; Liu, J.K. A square-type rotary ultrasonic motor with four driving feet. Sens. Actuator A Phys. 2012, 180, 113-119. [CrossRef]

32. Asumi, K.; Fukunaga, R.; Fujimura, T.; Kurosawa, M.K. Miniaturization of a V-shape transducer ultrasonic motor. Jpn. J. Appl. Phys. 2009, 48, 5. [CrossRef]

33. Liu, Y.X.; Chen, W.S.; Feng, P.L.; Liu, J.K. A rotary piezoelectric motor using bending vibrators. Sens. Actuator A Phys. 2013, 196, 48-54. [CrossRef]

34. Liu, Y.X.; Chen, W.S.; Yang, X.H.; Liu, J.K. A rotary piezoelectric actuator using the third and fourth bending vibration modes. IEEE Trans. Ind. Electron. 2014, 61, 4366-4373. [CrossRef]

35. Dabbagh, V.; Sarhan, A.A.D.; Akbari, J.; Mardi, N.A. Design and manufacturing of ultrasonic motor with in-plane and out-of-plane bending vibration modes of rectangular plate with large contact area. Measurement 2017, 109, 425-431. [CrossRef]

36. Liu, Y.X.; Yang, X.H.; Chen, W.S.; Xu, D.M. A bonded-type piezoelectric actuator using the first and second bending vibration modes. IEEE Trans. Ind. Electron. 2016, 63, 1676-1683. [CrossRef]

37. Liu, Y.X.; Liu, J.K.; Chen, W.S.; Shi, S.J. A U-shaped linear ultrasonic motor using longitudinal vibration transducers with double feet. IEEE Trans. Ultrason. Ferroelectr. Freq. Control 2012, 59, 981-989. [CrossRef] [PubMed]

(C) 2018 by the authors. Licensee MDPI, Basel, Switzerland. This article is an open access article distributed under the terms and conditions of the Creative Commons Attribution (CC BY) license (http://creativecommons.org/licenses/by/4.0/). 